\title{
Age de Carvalho: ex- sub, solitário
}

Age de Carvalho: former-, under-, lonely

Myriam ÁVILA ${ }^{1}$

Universidade Federal de Minas Gerais (UFMG)

RESUMO: Pela imagem do poeta solitário, este ensaio explora a presença da solidão e seu intercâmbio com a experiência de exílio, em poemas de Age de Carvalho que percorrem diferentes fases de sua poética. Dentre eles "No hotel", "De viagem", "48, no aeroporto". O texto recupera ainda o diálogo de sua poesia com a de Max Martins e Mário Faustino.

PALAVRAS-CHAVE: Poesia brasileira contemporânea, solidão, exílio.

ABSTRACT: Through the image of the lonely poet, this article discusses the theme of solitude and its connection with the experience of being in exile in poems by Age de Carvalho, in diferente stages of his poetry. Amongst them are "No hotel", "De viagem" and "48, no aeroporto". The essay also brings up the dialogue between his poetry and that of Max Martins and Mário Faustino.

KEYWORDS: Brazilian contemporary poetry, solitude, exile.

\section{O poeta}

Vigília, um rio presente

vertido e vertente

ecoa no fórum original:

ruína da careta latina,

Eneida incendiada, morto

o dador de fogo, nomen-numen

Passa o rio, ex -

sub, solitário (Age de carvalho -

O poeta é Virgílio e é também (lembrando Dante) o poeta-modelo ou poeta-guia. Mas no fim das contas, é o ser poeta qualquer e todos. O rio é presente e é passado, vertido, vertente, passa. Ruína, incêndio, morte - nada desfaz o poder do nome-numen, representado pelo fogo, que nem por estar no passado está apagado. O rio do esquecimento é o mesmo rio da memória, que ecoa num espaço que já não há. É nesse cenário de elementos incompatíveis - água e fogo - de abandono, partida e permanência que se dá a encruzilhada à qual se pode chamar poeta. Virgílio é o enigma que desafia os poetas de

\footnotetext{
${ }^{1}$ Professora do Programa de Pós-Graduação em Letras da UFMG.
} 
épocas posteriores, como Homero o desafiara. O poeta anterior, como propõe Harold Bloom, é um desafio ao poeta que sobrevém. Mas é também, diz Dante, um guia necessário e uma companhia.

A prática da leitura silenciosa e solitária, que para nós parece óbvia mas na verdade é muito recente, engendrou a imagem do poeta solitário. Age de Carvalho explora a ideia da solidão em vários de seus poemas, um dos quais mostramos abaixo:

\author{
No hotel \\ Só, \\ sem, não tendo \\ a quem \\ o que doar - \\ só \\ o ardor, \\ ninguém, \\ deste momento.
}

Com a paronomásia ardor/doar, Age lembra a importância do outro, o outro ideal do poeta, que é o leitor, para a criação. O poema sai com dificuldade, tartamudo (quem, que, guém), em ausência dessa necessária provocação de fora, de um olhar, de um confronto, de um corpo. O hotel torna mais conspícua a solidão, por ser um lugar público, onde tantos estão, por onde passam tantos. Agora já não temos a água; o poema é dominado pelo ar, dá passagem ao ar no seus brancos de silêncio. O fogo se encontra subjugado, apenas uma chama-ardor que o ar não chega a alimentar. Ex-, sub, solitário.

Se olharmos retroativamente para a poesia de Age de Carvalho, veremos que o elemento terra dominou toda uma fase de sua produção de juventude. O poeta fala de uma “confusão entre chão e carne". Os minerais, as cavernas, o subterrâneo lembram o cenário que Rilke desenha para a empresa frustrada de Orfeu em sua tentativa de trazer de volta à superfície a sua Eurídice. O espaço é, nessa fase, menos tênue, não há transparências e sim ocres e sanguíneas. Trata-se da "turva escrita das pedras", onde o fogo também comparece 
em forma da "palavra-vulcão" - um fogo explosivo, latente. O poeta se funde na paisagem: lembra que é carvalho, cepa, confluência de seivas. Ser natural, na natureza, o poeta acolhe a indisciplina e o descabelo da flora em turbilhão - amazônica:

As bananeiras indecentes alvoroçando suas pernas amplamente às serpentes de pluma: antros do inferno: as formações crueis, passando: nuvens

Trinta anos depois reencontramos uma bananeira ou encontramos uma sua parente: agora é bananeira-anã que brota delicadamente, discretamente na sala do apartamento vienense, orgulhosa de sua resistência ao ambiente europeu:

\author{
DE VIAGEM, \\ o apartamento vazio \\ em julho, sempre-sem, ninguém \\ em casa.
}

Estava que era, toda em-presente à sombra, em só ser, sozinha inchada de si:

A bananeira-anã, sua folha nova se desfraldando no centro da sala.

Como o poeta, a planta sobreviveu longe do seu solo essencial. E o ser só se transformou em só ser - estar sozinha é estar inchada de si, levantar seu estandarte verde em desafio às tílias e choupos. Já a primeira estrofe indica que a solidão não é propriamente indesejável: o apartamento vazio em julho, ninguém em casa. $\mathrm{O}$ isolamento e o silêncio, propícios à criação, não incomodam se se sabe que se terá companhia em breve. Em termos do poeta, significa que o poema - sua folha nova se desfraldando - aguardará tranquilo e aconchegado na página que os leitores se acheguem. E os primeiros leitores são sempre os pares, os amigos poetas.

Com um amigo poeta, Age de Carvalho fizera um livro em parceria, A fala entre parêntesis (1982), no estilo da renga, a poesia colaborativa japonesa. Para a composição da 
renga, poetas trabalham em pares ou em pequenos grupos, alternando-se na escrita de estrofes curtas. O parceiro de Age nessa aventura poética foi Max Martins, seu conterrâneo da geração anterior. O resultado é formidável; tão congeniais são os poetas que Benedito Nunes afirma, no prefácio, não conseguir separar os versos de cada um de seus amigos, a não ser pela caligrafia. No entanto, as linhas de cada um continuam sendo singularmente próprias de cada poeta, pois a afinidade eletiva consiste em se poder tanto estar junto como só. Como expõe um anagrama transidiomático de Age, sol/los, o que aquece e aconchega também “põe pra jambrar”, como se dizia antigamente.

Pouco depois da renga, Age parte para a Europa, onde se estabeleceu definitivamente, mas Max continua presente na sua poesia. No seu livro mais recente, Ainda: em viagem, a memória de suas antigas andanças com Max, por Salinas e Marahu, produz dois belos poemas, nos quais o poeta mais novo presenteia o mais velho com uma "segunda juventude" ("Max, segunda juventude").

Mas a companhia de que se cerca o poeta não exige esse convívio pessoal, presencial. Age está sempre consciente da figura precursora de Mário Faustino e da existência amiga de poetas só geograficamente distantes, como Augusto de Campos e André Vallias. Mesmo já em outra esfera, personalidades tão distintas como João Cabral de Melo Neto e Waly Salomão são igualmente convidadas para se juntar à entourage de Carvalho. E, com a competência de leitor poliglota, outros nomes (nomes-numens, para lembrar o poema visto acima) passam a se fazer cada vez mais familiares: Celan, Trakl, Jabès...

Mário de Andrade reconhecia em seus amigos escritores uma vida própria e uma vida emprestada por ele, quando os lembrava na solidão da escrita:

Não se trata apenas dessa pergunta, ou resposta, comum que nós, artistas, fazemos ao criar: "Será que o Carlos Drummond vai gostar disto?" "O Manuel Bandeira vai gostar deste poema", não. (...) O que eu sinto, ou o que faço é enquanto estou escrevendo, e até lendo, é ter o quarto habitado por, em geral um, raro dois amigos, que estão ali, juro que estão, lendo por cima dos meus ombros o que escrevo, me aconselhando, me dirigindo, me contradizendo para firmar bem, por amizade, por dedicação, as minhas argumentações. É tão bom... (Turista aprendiz, p.77)

Haroldo de Campos, em seu poema Renga em New York, propõe que esse gênero de poema não precisa ser praticado ao pé da letra, pois todo poema nasce da conjunção de 
almas de dezenas de poetas, em amizade que nada perde por ser virtual ou imaginada. $\mathrm{Na}$ Renga em New York irmanam-se Dante, Milton, Zukofski, Lorca, Maiakowski, Sousândrade em produtivo simpósio, num cenário de arranha-céus e mini-saias. Aí se insinua também a voz de João Cabral, com seus galos colaborativos a tecer a manhã, ressignificados por Haroldo: "um poeta tece a teia e outro poeta (o mesmo) teima e glosa".

Em que, portanto, consiste a solidão do poeta? Ovídio [Trístia], no exílio, lembra o ambiente literário em que sua poesia florescera, em Roma. Sem os amigos, sem a atmosfera da pátria, a vida parece insuportável. Resta-lhe dirigir-se ao leitor (que ainda era sincero, ainda não tinha adquirido a feição hipócrita que Baudelaire vê nele) e confiar nessa mensagem na garrafa que é o livro. No âmbito da prosa, o protagonista de $O$ amanuense Belmiro, de Cyro dos Anjos, ao ver desfeito o seu grupo de amigos intelectuais, percebe que é impossível escrever sem eles. Ovídio e Cyro, tão distantes no tempo como na literatura, são invocados aqui para propor a universalidade desse aspecto gregário da escrita criativa, essa “poesia com”. Se se escreve na solidão, essa é a solidão passageira do hotel ou do apartamento temporariamente vazio, a solidão de quem está "inchado de si” como a bananeira-anã.

Por que então o traço melancólico da evocação do poeta, emblematizado em Virgílio? Diz a lenda que Virgílio, pouco antes de morrer, pediu aos amigos que queimassem o manuscrito de sua epopeia, à qual havia dedicado onze anos de trabalho, na busca de uma perfeição inatingível. Os amigos a conservaram, inscrevendo-se assim na história do poema, responsabilizando-se por ele. O dador de fogo morto, a Eneida incendiada, todas as projeções de uma ruína, não impedem o rio de continuar a passar. E ele passa ex-, sub-, solitário. Se aí o título do poema (O poeta) se junta a esses sufixos (expoeta, sub-poeta) e se deixa qualificar pela solidão, a poesia mais recente de Age de Carvalho mostra que a solidão é o avesso do desastre: a Eneida não foi incendiada, a não ser pelo ardor do leitor, e o poeta é simplesmente um ex- ou um sub- solitário, de uma solidão entre parêntesis, de uma solidão povoada dos nomes-numens de outros poetas.

Essa visão mais solar da solidão do poeta em Age de Carvalho é corroborada mais uma vez em um poema que me atrai particularmente. Trata-se de “48, no aeroporto" 


\section{8, no aeroporto}

É chegada a hora, o estalo dum talo em flor ao abotoar o cinto, tempo partido sob os pés antes do take off:

cumpres anos, com a mangueira cantante enterrada no ar queres estar, és não és, decides e entre sinais luminosos da carne em trânsito decolas.

O "é chegada a hora" perde toda conotação dramática: é um los, um soltar-se, a decolagem. O tempo partido fica lá em embaixo; é o tempo cumprido, que já se pode deixar para trás. Quer-se estar ali: no ar, que suplanta o elemento terra, pois também no éter se pode enterrar uma bandeira (uma mangueira). A flor e o cinto de segurança se justapõem sem o conflito da matéria orgânica com o equipamento tecnológico. Quem está no comando és tu - o eu lírico retomado em segunda pessoa: tu decides, tu decolas. É a partida feliz, em plenitude de ser/não ser, para além do conflito. Uma calma bossanovística, uma economia sem sacrifício exalam da flor do poema. Nada me leva a descartar a ideia de que o cinto de segurança que garante a tranquilidade desse voo em vista é o aval tácito dos poetas amigos, tantas vezes chamados a compartilhar o espaço da página. Mesmo não nomeados, não é possível senti-los ali como espíritos-guias, como numens?

E, para fechar na mais luminosa das claves, não serão os prefixos ex- e sub- apenas o início das palavras êxito e sublime, nunca definitivamente atingidos mas sempre soprados em sedução à mão que escreve?

\section{Myriam Ávila}

Referências bibliográficas: 
ANDRADE, Mário de. Turista aprendiz. Estabelecimento do texto, introdução e notas de Telê Porto Ancona Lopez. São Paulo: Duas Cidades/Secretaria de Cultura, Esportes e Tecnologia, 1976.

CARVAlHO, Age de., MARTINS, Max. A fala entre parêntesis. Edições Grápho /Grafisa/Semec, Belém, 1982.

CARVALHO, Age de. Arena, areia. Grafisa/Edições Grápho, Belém, 1986.

CARVAlHO, Age de. Ainda: em viagem. Belém, Pará: ed. Ufpa, 2015. 